\title{
Communication \\ Pyro-Oil and Wax Recovery from Reclaimed Plastic Waste in a Continuous Auger Pyrolysis Reactor
}

\author{
Sultan Majed Al-Salem ${ }^{1} * \mathbb{C}$, Yang Yang ${ }^{2}$, Jiawei Wang ${ }^{2} \mathbb{D}$ and Gary Anthony Leeke ${ }^{3}$ \\ 1 Environment \& Life Sciences Research Centre, Kuwait Institute for Scientific Research (KISR), P.O. Box 24885, \\ Safat 13109, Kuwait \\ 2 Energy and Bioproducts Research Institute (EBRI), Aston University, Aston St., Birmingham B4 7ET, UK; \\ Y.YANG6@aston.ac.uk (Y.Y.); j.wang23@aston.ac.uk (J.W.) \\ 3 School of Chemical Engineering, University of Birmingham, Edgbaston, Birmingham B15 2TT, UK; \\ G.A.LEEKE@bham.ac.uk \\ * Correspondence: ssalem@kisr.edu.kw; Tel.: +965-2498-9000
}

Received: 29 February 2020; Accepted: 3 April 2020; Published: 20 April 2020

\begin{abstract}
The increasing global waste plastic pollution is urging people to take immediate actions on effective plastic recycling and processing. In this work, we report the results of processing reclaimed plastic wastes from unsanitary landfill site in Kuwait by using a bench scale continuous auger pyrolysis system. The plastic feedstock was characterised. After a simple thermal densification process, the material was fed to the pyrolysis system at $500{ }^{\circ} \mathrm{C}$. The pyro-oil and wax products were collected and characterised. The process mass balance was developed on dry basis, and the yields of pyro-oil, light wax, heavy wax and gases were $5.5,23.8,69.4$ and $1.3 \mathrm{wt} \%$, respectively. The findings have indicated that the reclamation of plastic waste from landfill was feasible in terms of the product distribution and characteristics. Further liquid analysis confirmed that the liquid products contained fractions that are comparable to petrol and diesel fuels. The wax products are viable and have potential application as coating, covering and lubrication.
\end{abstract}

Keywords: pyrolysis; plastic waste; landfilling; TGA; pyro-oil

\section{Introduction}

Plastics have become an essential commodity in our daily lives and their increasing consumption has led to the globally recognised problem of plastic waste accumulation [1]. The global production capacity of plastics has reached 348 million tonnes as of 2017, with an estimated 242 million tonnes of plastic waste generated in 2016 [2,3]. One of the most promising technologies that can reduce the accumulated plastic solid waste (PSW) is pyrolysis where the material is treated in an inert atmosphere under moderate to severe conditions $\left(<800^{\circ} \mathrm{C}\right)$ with the aim of producing solid char, tars (i.e., pyrolysis oil or pyro-oil; and waxes) and gaseous products [1]. Pyrolysis products are a promising alternative energy and chemical source that could compete with petrol (gasoline), diesel and waxes, all of which are highly desirable and competing in today's marketplace. The heating value of pyro-oil has been reported to reach up to $46.16 \mathrm{MJ} \mathrm{kg}^{-1}$, which surpasses various conventional fuel products [4]. In addition, landfilling has been associated with various associated problems that cause environmental burdens and stressors to soil, aquifers and air emissions. Plastics amongst the municipal solid waste (MSW), buried in various unsanitary sites the world over, could benefit from a standardised and a well-designed reclamation process that can best utilise the buried solid waste.

The concept of reclaiming landfill waste and treating it as a potential feedstock for various recycling and fuel recovery process has been popularised as of late. The general idea is to treat a landfill site as a source of value-added products and an economical futuristic venture for waste that could be 
easily introduced back to the market. However, such projects face a major obstacle, where fine materials require sophisticated separation techniques that are both energy intensive and costly to the recyclers [5]. Furthermore, these fine materials $(<20 \mathrm{~mm}$ in size) constitute a high fraction of the reclaimed waste ( $40 \%$ to $70 \%$ by weight) that require sieving in combination with magnetic separation [5]. Other than conventional mechanical treatment for the separation of reclaimed waste, wet-mechanical processing and sand washing have been reported to be effective in overcoming problems that arise from the heterogeneity of reclaimed waste [6]. The reader is referred to Wanka et al. [5] for a detailed description of the operation of wet jiggers equipped with sieves for fine particle separation of reclaimed waste. Quaghebeur et al. [7] described the typical mechanical treatment required for an industrial landfill mining operation. The mechanical treatment is aimed in this case to separate the various components of the waste using milling, sieving, crushing, magnetic and eddy current separation (of ferrous and non-ferrous metals) and density separation. Kaartinen et al. [8] reported the results of characterising reclaimed waste from a Finnish landfill site using mechanical treatment. The results of their work have indicated that mechanical treatment produces some $1 \%$ of metals that are magnetic in nature and presents challenges to the recovery of mixed metal components from textiles and plastics. On the other hand, Krook et al. [9] have emphasised the benefits of using off-site air knives and screening equipment for soil containing waste, which is freshly reclaimed from landfill sites.

The increasing attention that excavation and waste reclamation received lately has led to an increase in research to valorise waste components with high ash and calorific content received from landfill sites using thermochemical conversion (TCC). Zaini et al. [10] showed that refuse derived fuel (RDF) obtained from excavated waste combined with fine particles and treated using pyrolysis, produced modest oil and gas yields of 9-36 wt.\% and $15-26 \mathrm{wt} . \%$, respectively. This is in comparison to fresh waste samples which produces 53 and $24 \mathrm{wt} . \%$, respectively, attributed to the high ash content of the landfill feedstock material. The same study also reported results from gasification tests of landfill waste char. The work indicated that using fine sieves to sort the waste during ballistic separation will ultimately produce waste fuel with higher reactivity due to the higher ratio of metallic elements present in the landfill feedstock acting as catalysts. The document published by the European Commission entitled 'Roadmap to a Resource Efficient Europe' emphasises the role that waste should play in boosting the economy and viewing it as a resource by the year 2020 [11]. In a European context, there exists some 500,000 closed and active landfill sites on the continent; Burlakovs et al. [12] detailed their potential in a circular economy context for increasing the economy based on the recovered waste components. Closing material loops by recycling and landfill mining was discussed by Jones et al. [13] in a European context. Historic landfill sites were targeted in their study, as well as future landfill site projects. They conclude that a combination of energy production and land re-use was the best option to generate a high economical return coupled with environmental benefits. In this work, we report the results of treating reclaimed plastic waste from unsanitary landfill site in Kuwait using a continuous auger pyrolysis system. The plastic waste is firstly densified and fed to the reactor system, and the products obtained in terms of pyro-oil and waxes are characterised. This work also proposes a designed methodology to handle such waste stream whilst producing high fuel grade products overcoming deterioration issues associated with landfilled plastics [14]. The work is part of continuous research efforts in this research area, and to the best of our knowledge, the results here report for the first time continuous slow pyrolysis of reclaimed plastics from Kuwait in an auger reactor.

\section{Materials and Methods}

\subsection{Plastic Waste Acquirement}

Waste reclamation was conducted in an unsanitary landfill site within the borders of Kuwait following internationally recognised landfill reclamation and mining protocols [15]. The Mina Abdullah (MAB) landfill site (lat. $29^{\circ} 19^{\prime} 33.24^{\prime \prime} N$; long. $47^{\circ} 36^{\prime} 41.04^{\prime \prime} E$ ) was chosen for the waste mining procedure which was conducted on the 13th November 2018. The landfill has been in operation as part of three 
dedicated landfill sites in Kuwait that accept municipal solid waste (MSW) and is adjacent to an industrial landfill as well. The waste was reclaimed and mined using spade tractors from a singular landfill pit (1 meter in depth) of a six months old burial site to acquire a relatively fresh and homogenous sample. The waste pit characteristics, granulometric distribution, soil type, pollutants levels and landfill standard operating procedures can be found elsewhere [16-18].

\subsection{Waste Conditioning and Samples Preparation}

Reclaimed (mined) waste was transported on the same day of excavation within the span of four hours to laboratory conditioned facilities. The commingled waste was air blown and washed using a pressurised fresh water jet stream ( 2 bar) in a Jet- $X 8070$ Machine to remove all dust particles. The waste samples were then washed using regular tap water before and after leaving them to dry in open air environment for three continuous days. The samples were stored in laboratory conditions $\left(22-23^{\circ} \mathrm{C} / 50 \%\right.$ relative humidity) in sealed plastic containers before conditioning. Weighing scales were used to quantify the amount of the waste reclaimed as shown previously in Al-Salem et al. [18,19]. The waste was segregated into six categories following international protocols [20-23] as thus: plastics, metal and white goods, paper and cardboard, wood, organics and others. The plastic waste component (rigid and film) constituted some $20 \mathrm{wt} . \%$ of the total reclaimed materials. Thereafter, the PSW was shredded (after segregation from other waste components) using a three V knifes Vema machine operated at $580 \mathrm{rpm}$ speed (mesh size of $5 \mathrm{~mm}$ ). The waste samples were yielded as light flakes with an approximate size of $4 \mathrm{~mm}$ (manually measured) after three shredding cycles [18,24]. The readers are referred to the Supplementary Materials File for a pictorial depiction of the waste reclamation process and materials conditioning in Figure S1.

\subsection{Thermal Stability and Proximate Analysis}

The obtained post-shredded plastic waste was low in bulk density in film/flake form, which was attributed to the high content of light plastic (likely bags and packing waste) causing problems when further characterised in this study such as its instability in thermal analysis instruments and problems in reactor charging (Figure S1). Therefore, a simple densification process was carried out to densify the material. About $300 \mathrm{~g}$ of the as-received feedstock was placed in a sealed metal container, which was then placed in an oven heated to $150^{\circ} \mathrm{C}$ for $3 \mathrm{~h}$. Most of the low melting point plastic components were melted and aggregated to form much denser materials resulting in only physical changes to the feedstock (Figure S2). Thermogravimetric analysis (TGA) demonstrated the temperature range that causes volatilisation of the feedstock (see below), which was not surpassed during densification. The bulk densities of the feedstock were measured with respect to sample weights after placing them in $200 \mathrm{~mL}$ glass beaker. The recorded bulk density for the densified plastic was

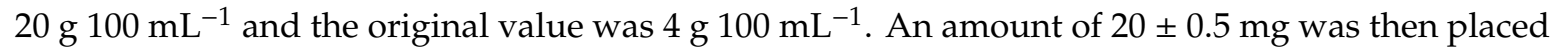
in a Metler-Toledo TGA/DSC 1 under a constant flow of pure nitrogen $\left(\mathrm{N}_{2}\right)$ gas at $30 \mathrm{~mL} \mathrm{~min}{ }^{-1}$ to determine the thermal stability of the material from room temperature to $800{ }^{\circ} \mathrm{C}$, surpassing all stages of the typical thermoplastic polymer degradation points. Proximate analysis was performed on the densified feedstock (dry basis). The ash content was measured in furnace at $575{ }^{\circ} \mathrm{C}$ and the fixed carbon was determined by averaging the pyrolysis TGA curves of the four major components present in the as-received feedstock. Volatile content was calculated as the difference between the raw material and the fixed carbon with ash.

\subsection{Pilot Plant Pyrolysis Runs and Products Identification}

Densified feedstock was processed in a bench scale pyrolysis system at $500{ }^{\circ} \mathrm{C}$. The system described below consists of a feeding section (arrangement) for the continuous auger pyrolysis reactor, followed by a solid product collection vessel and a liquid product condensation and collection system (Figure 1). The tube of the reactor is of a $26.5 \mathrm{~mm}$ diameter and a $500 \mathrm{~mm}$ length. The heating is conducted using an external source (electric furnace of a Carbolite VST 12/400 model) with a supply 
of power capacity of $2 \mathrm{~kW}$. Purging with $\mathrm{N}_{2}$ gas was conducted before each experimental run to ensure the elimination of any oxygen presence. The material was fed continuously $\left(100 \mathrm{~g} \mathrm{~h}^{-1}\right)$ through a chute, which was later transported by an auger screw among the body of the reactor. The gases passed through a water condenser operated at $5{ }^{\circ} \mathrm{C}$ and two dry ice condensers operated at $-70^{\circ} \mathrm{C}$. The residence time of solids was approximately 10 minutes and the vapours' residence time were estimated as $15 \mathrm{~s}$.

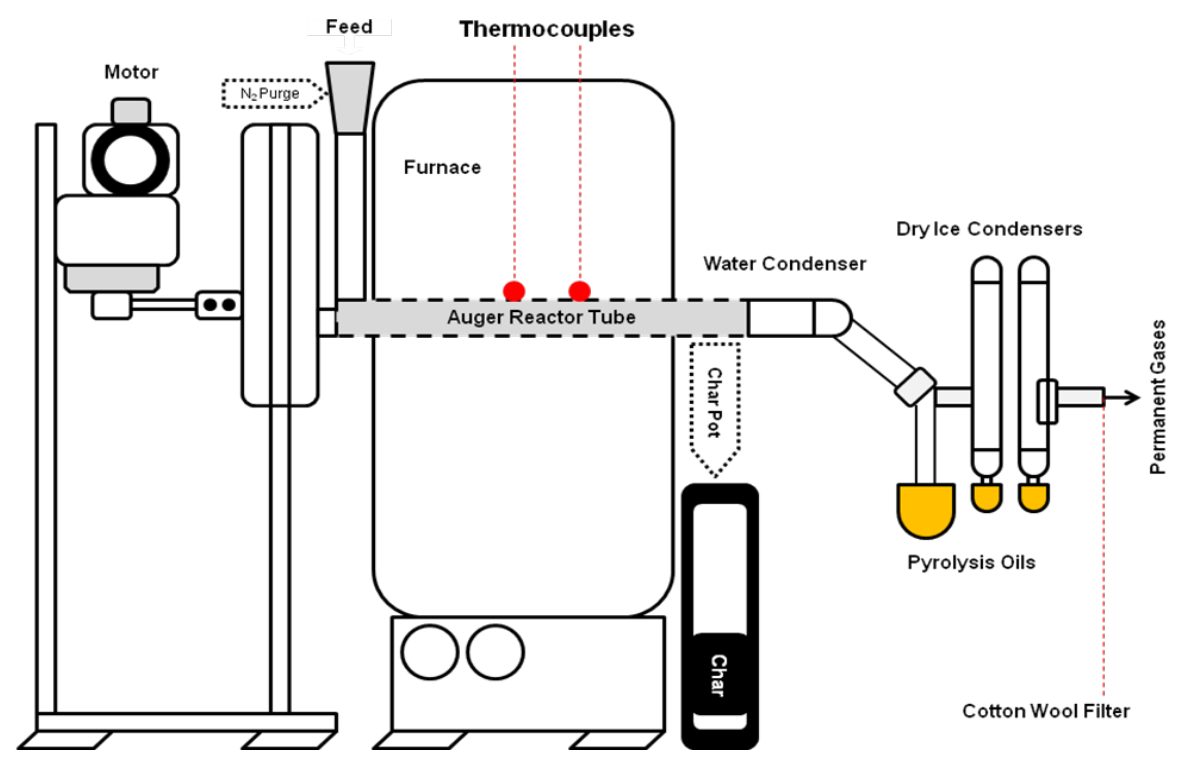

Figure 1. Schematic diagram showing the various parts of the auger paralysis reactor system used in this study.

The samples herein referred to as liquid, light wax and heavy wax were submitted for gas chromatography-mass spectrometry analysis (Agilent GC-MS). The samples were filtered before submission with the two wax samples being dissolved in toluene first. The GC program was a linear heating rate of $10^{\circ} \mathrm{C} \mathrm{min}-1$ from $50{ }^{\circ} \mathrm{C}$ to $300{ }^{\circ} \mathrm{C}$ where it was held for 6 minutes [24]. The samples provided were shown to be of a fairly typical nature for high density polyethylene (HDPE) and low density polyethylene (LDPE) pyrolysis oils [18]. They consist of mainly linear hydrocarbons of ranging in size from a carbon chain length of $4\left(\mathrm{C}_{4}\right)$ to above $33\left(\mathrm{C}_{33}\right)$. The analysis of higher hydrocarbons is not possible by the GC-MS method due to temperature limitations. These linear hydrocarbons are made up of $\alpha, \omega$-dienes, olefins and paraffins. Also present were branched and cyclic hydrocarbons and some limited detection of single ringed aromatics.

\section{Results}

\subsection{Plastic Waste Stability and Proximate Analysis}

The thermal analysis results conducted on the plastic waste is shown in Figure S3. The four dominant components by weight (and also colour) in the material showed distinctive thermograms that could be attributed to various components of plastic solid waste (PSW) typically available in the municipal stream $[1,24,25]$ (Figure S2). The onset and endset temperatures (identified by the thermograms) associate these components with rigid (hard) plastics (e.g., PS), mixed municipal plastic waste (MPW) (e.g., mixture of PE, PET, PS etc), plastic film waste (PFW) (e.g., LDPE) and end of life tyre (ELTs) $[18,25,26]$ (Figure S3a). The majority of the materials were also previously identified as polyolefinic (PO) polymers in origin, namely polyethylene (PE) [25]. Readers are referred to our previous results and discussion detailed in Al-Salem et al. [18,24]. Based on the thermogram obtained, it is clearly seen that the thermal decomposition of the feedstock started at $350{ }^{\circ} \mathrm{C}$ and was completed at $500{ }^{\circ} \mathrm{C}$ (Figure S3b). Hence, the pyrolysis temperature for the MSW feedstock was chosen as $500{ }^{\circ} \mathrm{C}$. 
The proximate analysis in this work revealed that the material possesses $7.4 \%$ of ash content, which is related to the inorganic fraction of the waste material. This is opposed to the volatiles, which were estimated to be $80.8 \%$, and the fixed carbon content, estimated at $11.2 \%$, which are related to the organic fraction of the reclaimed PSW. Zhou et al. [27] reported a low percentage of average ash content $(0.48 \%)$ and high volatiles $(99.44 \%)$ in Chinese plastic waste reclaimed from landfill sites. On the other hand, Mutua et al. [28] showed that ash content can reach up to $6 \%$ in mixed plastic waste. Furthermore, ash was reported to be as high as $28.2 \%$ in previous work for reclaimed plastic waste [29]. The decomposable fraction of the reclaimed waste in this study points towards the fact that it is still considered of integrity or typically termed as fresh waste due to the high volatile content. The waste, which was reclaimed after six months of burial and plastic waste in Kuwait, has a single life cycle that is typically associated with its valorisation routes [30]. This is also complimented by the fact that the material reported in this work has a high fixed carbon content $(11.8 \%)$ when compared to other studies showing plastics buried for prolonged durations [27].

\subsection{Mass Balance and Pyro-Oil/Wax Analysis}

The pyrolysis of the plastic waste was conducted in the system aforementioned with a nominal operating temperature of $500{ }^{\circ} \mathrm{C}$. The mass balances (wt.\% on a dry feed basis) was calculated based on the mass of waste feedstock processed and the final products collected of pyrolysis (e.g., liquid, solids and non-condensable gases). During the pyrolysis run, it was found that the liquid product naturally separated into two phases, i.e., a liquid phase and a waxy phase (Figure S4). The liquid product was collected in bottles, while most of the waxy product (referred to as light wax) remained on the inner surface of the water condenser (Figure S5). After opening the char pot, no solid char was found; instead, there was a large amount of agglomerated heavy wax. The overall mass balance of the run is shown in Table 1.

Table 1. Overall Process Mass Balance in The Reactor System.

\begin{tabular}{ccc}
\hline & Unit & Value \\
\hline Feed Rate & $\mathrm{g} \mathrm{h}^{-1}$ & 300.0 \\
Total Feed & $\mathrm{g}$ & 300.6 \\
\hline & Yield & \\
\hline Liquid (Pyro-oil) & wt. $\%$ & 5.5 \\
Light Wax & wt. $\%$ & 23.8 \\
Heavy Wax & wt. $\%$ & 69.4 \\
Gas & $w t . \%$ & 1.3 \\
Gas & $\mathrm{dm}^{3}$ & 3.1 \\
\hline
\end{tabular}

The yield of the total pyrolysis oil (pyro-oil) was estimated to be less than $6 \mathrm{wt.} \%$ (Table 1). However, the collective tars fraction (oil and wax) has totalled at almost $94 \mathrm{wt} . \%$ of the total mass balance indicating high conversion in the continuous pyrolysis reactor set-up. This also indicates that it is possible to treat plastic waste originating from landfill mining operation in such a way to decrease the accumulation of the solid waste and reduce the environmental burdens associated with landfilling. The conversion rate of the plastic waste to pyro-oil in this study did not surpass previous attempts of pyrolysis on various types of biomass (maximum of $55 \mathrm{wt} . \%$ ) [31], used cooking oil/waste HDPE (50 wt.\%) [32] and virgin commercial grade HDPE ( $<60 \mathrm{wt} . \%-$ tars) [33]. This could be attributed to the 10 minutes' residence time of the plastic in the reactor and the nature of the feedstock material (i.e., plastic waste), which may be degraded, and with a substantial initial deterioration of volatiles when exposed to pyrolytic conditions. Furthermore, the pyro-oil, light and heavy waxes were subjected to GC-MS analysis. The samples were filtered before submission with the two wax samples being dissolved in toluene first. The chromatogram for the pyro-oil and wax products are appended in Figure S6. 
The GC-MS of the pyro-oil sample shows a regular display of triplets which is indicative of PE depolymerisation [34]. These triplets were identified as $\alpha, \omega$-diene, followed by the olefin and then the paraffin of that very same carbon number within the same spectrum (Figure S6a,b). In addition, the peaks in-between show the presence of branched hydrocarbons and were clearly observed along the spectrum. By zooming in on the lower region of the spectrum, a very crowded spectrum is noted, which reveals the triplet structure, as well as many additional peaks (Figure S6c). Within this region of the spectrum, a higher proportion of branched and cyclic components were observed, especially when compared to other regions of the considered full spectrum analysis at longer times. The identification of compounds included the detection of small traces of benzene and toluene chemical, which were potentially derived from packing plastics including PS and PET. These were the only aromatics identified, though there are more suitable analyses to test for aromatics. Furthermore, and in an effort to determine fuel range compounds, the area of the peaks was integrated and summed (in that order) for the broad categories that are representative of petrol (gasoline), diesel fuels and waxy materials, shown in Table 2 below.

Table 2. Distribution of Hydrocarbons in Each Pyro-oil Sample and Percentile Area Distribution in Petrol, Diesel and Wax Categories.

\begin{tabular}{ccccccc}
\hline & \multicolumn{2}{c}{ Liquid } & \multicolumn{2}{c}{ Light Wax } & \multicolumn{2}{c}{ Heavy Wax } \\
\hline \multirow{2}{*}{ Carbon\# Range } & \multicolumn{2}{c}{$\mathbf{C}_{\mathbf{4}}-\mathrm{C}_{\mathbf{3 1}}$} & \multicolumn{2}{c}{$\mathrm{C}_{\mathbf{4}}-\mathrm{C}_{\mathbf{3 5}}$} & \multicolumn{2}{c}{$\mathrm{C}_{\mathbf{1 0}}-\mathrm{C}_{\mathbf{3 5}}$} \\
\cline { 2 - 7 } & $\mathbf{( \% )}$ & Ratio & $\mathbf{( \% )}$ & Ratio & $\mathbf{( \% )}$ & Ratio \\
\hline Petrol $\left(\mathrm{C}_{4}-\mathrm{C}_{9}\right)$ & 51.59 & 5.02 & 22.70 & 0.78 & 0.00 & 0.00 \\
Diesel $\left.\mathrm{C}_{10}-\mathrm{C}_{19}\right)$ & 36.12 & 3.57 & 49.88 & 1.72 & 16.79 & 0.20 \\
Wax $\left(\mathrm{C}_{20+}\right)$ & 10.17 & 1.00 & 29.08 & 1.00 & 83.21 & 1.00 \\
\hline
\end{tabular}

The majority of the pyro-oil eluted in the range of $\mathrm{C}_{4}-\mathrm{C}_{9}$. It was also noted that the GC-MS program used showed that the heavy hydrocarbons did not elute with a substantial differentiation from the baseline. This should be taken into consideration when the heavy components are analysed in the wax samples. The integration of the 3 to 6 minutes' interval were discarded for the assignment of groups in Table 2 due to the elution of toluene which was used as a solvent for the wax samples. Furthermore, the light wax showed a broad distribution which was very similar to the liquid sample.

Comparing to the diesel and wax fraction of the pyro-oil, the wax product has increased significantly (Table 2). The samples also elute up to $C_{35}$ where the peaks tail to almost zero; thus, there may be an underestimation of heavy component hydrocarbons. Furthermore, the heavy wax peaks are not present in the pre-toluene section of the chromatograph and the first differential peak is seen at $\mathrm{C}_{10}$ (Figure S6d,e). It is also suggested that in the future a higher temperature program is to be used to elute the wax samples agglomerated in the reactor (i.e., heavy wax), similar to ASTM-D-6352 [35]. Nonetheless, the program used in this study is still considered to be suitable for the analysis, as it meets the criteria for plastics depolymerisation analysis as shown previously in Lund et al. [34]. Kumar et al. [36] showed that thermal pyrolysis promotes gas and char production over tars with a low gasoline range selectivity. In this work, the total pyro-oil and wax (tars) yield was almost equivalent to $94 \mathrm{wt} . \%$ with high petrol range conversion. This indicated that plastic waste from Kuwait could be promoted as a good feedstock for chemical wax production with high fuel fractions. Furthermore, catalytic pyrolysis could be also used in the future to enhance the thermal cracking and increase product selectivity especially promoting petrol range over diesel at lower operating temperatures. This on the other hand could result in a lower energy consumption process for the reactor set-up used.

The results of this study indicate that it is possible to recover products from plastic waste reclaimed from landfill by pyrolysis. The recovery procedure to prepare the material for thermal pyrolysis was lengthy and the recovered feedstock required densification prior to pyrolysis. The results of this study indicate that it is possible to recover products from plastic waste reclaimed from landfill by pyrolysis. The recovery procedure to prepare the material for thermal pyrolysis was lengthy and the recovered 
feedstock required densification prior to pyrolysis. The procedure could also be scaled up using mechanical treatment to improve recoverability and processing time [5]. Mechanical set-ups could also be installed off-site to develop an integrated energy from waste schemes for landfill reclamation. The initial thermal pyrolysis experiments on samples from the Mina Abdullah site show that the materials have to undergo a low temperature densification procedure, as they are difficult to feed into the auger reactor as films. However, these pre-treatment processes could be mechanised and automated on a commercial scale operation. Many pyrolysis processes use a pelleting pre-treatment to prepare the materials so that consistent feeding and heating rates can be attained. The products from the pyrolysis show a large proportion of light and heavy waxes, which were viscous in nature and made their collection challenging. The production of such products is due to the high thermal resistance of the plastic materials and insufficient cracking of their polymer chains in the reactor during slow pyrolysis. Wax is a viable product and has uses in coatings, coverings and lubrication; however, the market share is small when compared to liquid fuels and chemicals. However, significant growth is forecast from 2018 to 2023 as demand from the cosmetic industry grows with $70 \%$ of wax originating from petroleum sources [37]. Fast pyrolysis can only be achieved if the samples are communited to reduce particle size to $100 \mu \mathrm{m}$ by cryomilling. This has shown to be successful on small batches of material prepared for TGA-IR [24]. Approximately $100 \mathrm{~g}$ of material is required to conduct the fast pyrolysis test. The communition of the samples has future implications on the economics of a commercial process. Furthermore, the work shows potential for materials reclaimed from landfill sites to be viable in the recycling industry over mechanical recycling schemes typically undertaken for PSW [38]. It could also promote plastic waste as a feedstock material that could be utilised in the future for the production of renewable energy and fuels in the form of petrol and diesel from solid waste. Mechanical recycling of fresh or reclaimed waste will render the products to have a certain life-span restricted with the number of recycling and thermal loops that the final product is subjected to. Ultimately, mechanical recycling will also utilise the use of virgin plastic resins to enhance the properties of the reclaimed waste. These factors are eliminated when fuel (or chemical) recovery is targeted such as the proposed work in this study. Furthermore, fuel recovery would also reduce the dependence on fossil fuel used to power mechanical facilities used to physically treat and recycle the PSW. It should also be kept in mind that the origin of the PSW treated in this work is of fossil fuel; however, since the production of a fuel grade product is achieved from a sustainable feedstock, the term sustainable fuel is applicable to the case at hand [1]. Treatment of waste can result in various fuels and chemicals that match fossil-derived ones, such as products obtained from the pyrolysis of reclaimed PSW. The environmental and economical value of such work warrants further investigation. Further physical, chemical and energy value characteristics studies should also take place to characterise the fuel properties of the obtained pyrolysis products in this work. The work in this study is also in line with recent findings that emphasise thermal treatment as a solution to reclaimed PSW, as a major part to circular economy action plans in the near future [39]. It also complements recent findings published as of late focusing on overcoming ash content to have better yield results post treatment using TCC technologies $[10,39]$.

\section{Conclusions}

The findings show that the reclamation of plastic waste from landfill and its conversion into hydrocarbon products was feasible in terms of the process mass balance and the product characterisation. A pre-treatment step was required to prepare the reclaimed materials for pyrolysis in the Auger reactor. Pre-treatment was dedicated to washing and separating the various components of the waste reclaimed from the landfill site. This step could be further scaled up with various mechanical schemes that could ease the operation and work in future work. It should also be given priority in techno-economic analysis coupled to determine the benefit of such treatment against conventional ones (e.g., incineration, conventional recycling, etc). The products recovered from the slow pyrolysis yielded pyro-oil and viscous wax-like fractions with high conversion yields reaching almost $94 \mathrm{wt}$. $\%$. However, fast pyrolysis 
may be able to produce oils with less wax content and lower viscosity. The proximate analysis of samples gave an ash content of $7.4 \mathrm{wt} . \%$; the composition of ash, its effect on the pyrolysis process and the fate of the ash components in the pyrolysis process need further investigation to determine their impact on the product yield.

Supplementary Materials: The following are available online at http:/www.mdpi.com/1996-1073/13/8/2040/s1, Figure S1: Pictorial Depiction of the Waste Reclamation Process Showing; (a) Allocation of Waste Landfill Ditch and Burial Pit, (b) Mining Procedure and Waste Reclamation, (c) Solid Waste Segregation After Initial Washing, (d) Shredding Machine Used and, finally, (e) Acquired Plastic Product from the Waste Shredding Process; Figure S2: Sample from the Mina Abdullah Site for the Pyrolysis Experiment (Left: as-received; Right: after densification), Figure S3: (a) TGA Curves of four Difference Components Selected in the As-received Feedstock (C1: Hard Plastic; C2: Mixed Plastic Fraction; C3: Light Thin Films, C4: Tyre Rubber), (b) Averaged TGA Curves of Four Difference Components Selected in the As-received Feedstock; Figure S4: Pyrolysis Liquid Collected After the Run (Left: Liquid Fraction; Right: Light Waxy Fraction), Figure S5: Pyrolysis Liquid Produced During the Run (a. At the Beginning-Start of Experimental Run; b. At the End of the Run)-Note the Heavy Fraction Liquid in the Water Condenser, Figure S6. (a) Liquid Sample Chromatogram Full Range Showing Carbon Numbers; (b) Liquid Sample Chromatogram Zoom Showing Triplet Structure for C10 to C13; (c) Liquid Sample Chromatogram Zoom Showing Carbon Numbers in The Lights Region; (d) Light Wax Sample Chromatogram Full Range Showing Carbon Numbers; (e) Heavy Wax Sample Chromatogram Full Range Showing Carbon Numbers.

Author Contributions: Conceptualisation, S.M.A.-S.; Methodology, S.M.A.-S., G.A.L., Y.Y. and J.W.; Validation, S.M.A.-S., G.A.L. and J.W.; Formal Analysis, S.M.A.-S., G.A.L., Y.Y. and J.W.; Writing-Original Draft, S.M.A.-S.; Writing-Review and Editing, S.M.A.-S., G.A.L. and J.W. All authors have read and agreed to the published version of the manuscript.

Funding: The authors would like to thank the Kuwait Institute for Scientific Research (KISR) and the British Council/UK-Gulf Institutional Links for funding and supporting this research project (EM103C) through Grant \#2793-5936-4.

Acknowledgments: We would like to thank Kuwait Municipality (KM) for their support towards the field work activities reported in this article. The authors would like to thank the three reviewers to this article for their immense help and input to the article by providing comments that we believe have enriched the article's content.

Conflicts of Interest: The authors declare no conflict of interest.

\section{References}

1. Al-Salem, S.M.; Lettieri, P.; Baeyens, J. Recycling and recovery routes of plastic solid waste (PSW): A review. Waste Manag. 2009, 29, 2625-2643. [CrossRef]

2. Plastics Europe. Plastics-the Facts 2018: An Analysis of European Plastics Production, Demand and Waste Data; Plastics Europe: Puteaux, French, 2018.

3. Kaza, S.; Yao, L.; Bhada-Tata, P.; Van Woerden, F. What a Waste 2.0: A Global Snapshot of Solid Waste Management to 2050, Urban Development Serie; World Bank: Washington, DC, USA, 2018.

4. Kunwar, B.; Cheng, H.N.; Chandrashekaran, S.R.; Sharma, B.K. Plastics to fuel: A review. Sci. Total Environ. 2016, 54, 421-4228. [CrossRef]

5. Wanka, S.; Münnich, K.; Fricke, K. Landfill Mining-Wet mechanical treatment of fine MSW with a wet jigger. Waste Manag. 2017, 59, 316-323. [CrossRef] [PubMed]

6. Cossu, R.; Lai, T. Washing of waste prior to landfilling. Waste Manag. 2012, 32, 869-878. [CrossRef]

7. Quaghebeur, M.; Laenen, B.; Geysen, D.; Nielsen, P.; Pontikes, Y.; Van Gerven, T.; Spooren, J. Characterization of landfilled materials: Screening of the enhanced landfill mining potential. J. Clean. Produc. 2013, 55, 72-83. [CrossRef]

8. Kaartinen, T.; Sormunen, K.; Rintala, J. Case study on sampling, processing and characterization of landfilled municipal solid waste in the view of landfill mining. J. Clean. Produc. 2013, 55, 56-66. [CrossRef]

9. Krook, J; Svensson, N.; Eklund, M. Landfill mining: A critical review of two decades of research. Waste Manag. 2012, 32, 513-520. [CrossRef]

10. Zaini, I.N.; López, C.G.; Pretz, T.; Yang, W.; Jönsson, P.G. Characterization of pyrolysis products of high-ash excavated-waste and its char gasification reactivity and kinetics under a steam atmosphere. Waste Manag. 2019, 97, 149-163. [CrossRef]

11. Roadmap to a Resource Efficient Europe EU Commission, Resource Efficiency. 2011. Available online: http: //ec.europa.eu/environment/resource_efficiency/about/roadmap/index_en.htm (accessed on 17 March 2020). 
12. Burlakovs, J.; Kriipsalu, M.; Klavins, M.; Bhatnagar, A.; Vincevica-Gaile, Z.; Stenis, J.; Jani, Y.; Mykhaylenko, V.; Denafas, G.; Turkadze, T.; et al. Paradigms on landfill mining: From dump site scavenging to ecosystem services revitalization. Resour. Conserv. Recycl. 2017, 123, 73-84. [CrossRef]

13. Jones, P.T.; Geysen, D.; Tielemans, Y.; Van Passel, S.; Pontikes, Y.; Blanpain, B.; Quaghebeur, M.; Hoekstra, N. Enhanced Landfill Mining in view of multiple resource recovery: A critical review. J. Clean. Prod. 2013, 55, 45-55. [CrossRef]

14. Canopoli, L.; Coulon, F.; Wagland, S.T. Degradation of excavated polyethylene and polypropylene waste from landfill. Sci. Total. Environ. 2019, 698, 134125. [CrossRef] [PubMed]

15. Mor, S.; Ravindra, K.; De Visscher, A.; Dahiya, R.P.; Chandra, A. Municipal solid waste characterization and its assessment for potential methane generation: A case study. Sci. Total Environ. 2006, 371, 1-10. [CrossRef] [PubMed]

16. Al-Salem, S.M.; Al-Nasser, A.; Al-Dhafeeri, A.T. Multi-Variable Regression Analysis for the Solid Waste Generation in the State of Kuwait. Process Safe. Environ. Protect. 2018, 119, 172-180. [CrossRef]

17. Al-Sarawi, M.A.; Massoud, M.S.; Wahba, S.A. Physical properties as indicators of oil penetration in soils contaminated with oil lakes in the Greater Burgan oil fields, Kuwait. Water Air Soil Pollut. 1998, 102, 1-15. [CrossRef]

18. Al-Salem, S.M.; Leeke, G.A.; Karam, H.J.; Al-Enzi, R.; Al-Dhafeeri, A.T.; Wang, J. Investigating the thermal characteristics of reclaimed solid waste from a landfill site using thermogravimetry. In Proceedings of the International Conference on Environmental Pollution and Pollution Control of the World Academy of Science, Engineering and Technology (WASET), London, UK, 20-21 January 2021; pp. 1237-1276.

19. Al-Salem, S.; Leeke, G.; Wang, J.; Al-Enezi, R.; Karam, H.; Al-Wadi, M.; Al-Dhafeeri, A.; Boota, A. Solar Powered Fast Pyrolysis for Producing Bio-Oils from Municipal Solid Waste in the State of Kuwait, Annual Progress Report, KISR No. 15721, Project Code: EM103C; Kuwait Institute for Scientific Research (KISR): Kuwait City, Kuwait, 2019.

20. Al-Salem, S.; Al-Nasser, A.; Al-Wadi, M.; Al-Foudaree, M.; Al-Qassimi, M.; Al-Dhafeeri, A.; Asiri, F.; Sultan, H.; Karam, H. Established Protocols and Research Methods Acquired In The Waste Management Research Unit (WMRU), Technical Report, KISR no. 14854, Project Code: P-KISR-06-11; Kuwait Institute for Scientific Research (KISR): Kuwait City, Kuwait, 2018.

21. World Health Organization. Handling Solid Wastes in Developing Countries; World Health Organization: Alexandria, Egypt, 1988.

22. Al-Khatib, I.A.; Monou, M.; Abu Zahra, A.S.F.; Shaheen, H.Q.; Kassinos, D. Solid waste characterization, quantification and management practices in developing countries. A case study: Nablus district-Palestine. J. Environ. Manag. 2010, 91, 1131-1138. [CrossRef]

23. Al-Khatib, I.A.; Fkhidah, I.A.; Khatib, J.I.; Kontogianni, S. Implementation of a multi-variable regression analysis in the assessment of the generation rate and composition of hospital solid waste for the design of a sustainable management system in developing countries. Waste Manag. Res. 2010, 34, 225-234. [CrossRef]

24. Al-Salem, S.M.; Leeke, G.A.; Al-Enezi, R.; Sultan, H.H.; Karam, H.J.; Al-Wadi, M.H.; Al-Dhafeeri, A.T.; Boota, A.A.; Wang, J. Potential for thermal and solar power pyrolysis in treating reclaimed real life solid waste from a landfill disposal site. In Proceedings of the 17th International Waste Management and Landfill Symposium (Sardinia'19), Sardinia, Italy, 30 September-4 October 2019.

25. Al-Salem, S.; Behbehani, M.; Karam, H.; Al-Rowaih, S.; Asiri, F. On the Kinetics of Degradation Reaction Determined Post Accelerated Weathering of Polyolefin Plastic Waste Blends. Int. J. Environ. Res. Public Health 2019, 16, 395. [CrossRef]

26. Al-Salem, S.M.; Lettieri, P.; Baeyens, J. Kinetics and product distribution of end of life tyres (ELTs) pyrolysis: A novel approach in polyisoprene and SBR thermal cracking. J. Hazard. Maters. 2009, 172, 1690-1694. [CrossRef]

27. Zhou, C.; Fang, W.; Xu, W.; Cao, A.; Wang, R. Characteristics and the recovery potential of plastic wastes obtained from landfill mining. J. Clean. Produc. 2014, 80, 80-86. [CrossRef]

28. Mutua, N.A.; Ouma, A.B.; Atieno, O.S. Kinetic study of the thermal decomposition for mixed municipal solid waste using thermogravimetric analysis. Preiod. Eng. Nat. Sci. 2017, 5, 355-363.

29. Adrados, A.; de Marco, I.; Caballero, B.M.; López, A.; Laresgoiti, M.F.; Torres, A. Pyrolysis of plastic packaging waste: A comparison of plastic residuals from material recovery facilities with simulated plastic waste. Waste Manag. 2012, 32, 826-832. [CrossRef] [PubMed] 
30. Al-Salem, S.M.; Abraham, G.; Al-Qabandi, O.A.; Dashti, A.M. Investigating the effect of accelerated weathering on the mechanical and physical properties of high content plastic solid waste (PSW) blends with virgin linear low density polyethylene (LLDPE). Polym. Test. 2015, 46, 116-121. [CrossRef]

31. Mahari, W.A.W.; Chong, C.T.; Cheng, C.K.; Lee, C.L.; Hendrata, K.; Yek, P.N.Y.; Ma, N.L.; Lam, S.S. Production of value-added liquid fuel via microwave co-pyrolysis of used frying oil and plastic waste. Energy 2018, 162, 309-317. [CrossRef]

32. Shah, A.; Darr, M.J.; Dalluge, D.; Medic, D.; Webster, K.; Brown, R.C. Physicochemical properties of bio-oil and biochar produced by fast pyrolysis of stored single-pass corn stover and cobs. Bioresource Techn. 2012, 125, 348-352. [CrossRef] [PubMed]

33. Al-Salem, S.M. Thermal pyrolysis of high density polyethylene (HDPE) in a novel fixed bed reactor system for the production of high value gasoline range hydrocarbons (HC). Process Safe. Environ. Protect. 2019, 127, 171-179. [CrossRef]

34. Lund, L.M.; Sandercock, P.M.L.; Basara, G.J.; Austin, C.C. Investigation of various polymeric materials for set-point temperature calibration in pyrolysis-gas chromatography-mass spectrometry (Py-GC-MS). J. Anal. App. Pyrolysis 2008, 82, 129-133. [CrossRef]

35. ASTM D-6352-15. Standard Test Method for Boiling Range Distribution of Petroleum Distillates in Boiling Range from $174^{\circ} \mathrm{C}$ to $700^{\circ} \mathrm{C}$ by Gas Chromatography; ASTM: West Conshohocken, PA, USA, 2015.

36. Kumar, S.; Panda, A.K.; Singh, R.K. A review on tertiary recycling of high-density polyethylene to fuel. Resourc. Conserv. Recy. 2011, 55, 893-910.

37. Wax Market-Growth, Trends, and Forecast (2020-2025). 2019. Available online: http://mordorintelligence. com/industry-reports/waxes-market (accessed on 3 April 2020).

38. Al-Salem, S.M. Influential parameters on natural weathering under harsh climatic conditions of mechanically recycled plastic film specimens. J. Environ. Manag. 2019, 230, 355-365. [CrossRef]

39. Burlakovs, J.; Kriipsalu, M.; Porshnov, D.; Jani, Y.; Ozols, V.; Pehme, K.-M.; Rudovica, V.; Grinfelde, I.; Pilecka, J.; Vincevica-Gaile, Z.; et al. Gateway of Landfilled Plastic Waste Towards Circular Economy in Europe. Separations 2019, 6, 25. [CrossRef]

(C) 2020 by the authors. Licensee MDPI, Basel, Switzerland. This article is an open access article distributed under the terms and conditions of the Creative Commons Attribution (CC BY) license (http://creativecommons.org/licenses/by/4.0/). 